\title{
Prevalence and Cropping System Impacts on Soybean Vein Necrosis Disease in Delaware Soybeans
}

\author{
Nathan M. Kleczewski, ${ }^{\dagger}$ University of Delaware, Department of Plant and Soil Science, Newark, 19716
}

Accepted for publication 11 December 2017.

Since 2008, soybean vein necrosis disease (SVN) caused by Soybean vein necrosis virus (SVNV; family Bunyaviridae; genus Tospovirus [Zhou et al. 2011]) has become widespread throughout soybean (Glycine max [L.] Merr.) production areas in the United States (Zhou and Tzanetakis 2013). The virus is spread primarily by thrips (order: Thysanoptera) (Keough et al. 2016), although seed transmission has been detected (Groves et al. 2016). SVN symptoms include foliar chlorosis starting at the leaf vein, which turns necrotic with age. In severe cases, defoliation may occur. Although no consistent impacts of SVN on soybean yield have been reported, the virus can change soybean quality. For example, recent research indicates SVN can reduce soybean oil concentration by $0.67 \%$ (Anderson et al. 2017). This result is of particular interest in the Chesapeake Bay region of the mid-Atlantic because the production of high-oleic acid soybeans is becoming increasingly common. Growers planting high-oleic acid soybeans are paid a premium, but this premium is contingent on soybean quality meeting purchaser specifications. To date, the incidence of SVN in this region is uncharacterized, and the effects of the cropping system (i.e., full-season soybean versus double-cropped soybean following small grains) are unknown. We speculate that SVN would be widespread in Delaware and more severe in double-cropped soybean compared with full-season soybean as a result of delayed planting.

From 2015 to 2017, 88 soybean fields (48 full season, 40 double cropped) throughout Delaware were assessed for SVN incidence. During this time growing conditions were typical for Delaware with no significant temperature or rain events. Fields ranged between approximately 20 and 81 ha. Each field was visited twice, with visits targeting soybean vegetative (V3 to V5) and early reproductive (R1 to R3) soybean growth stages (Fehr and Caviness 1977). Fullseason fields were sampled at June 29 to July 1 and July 19 to 22 (2015), July 9 and August 3 (2016), and June 27 and July 26 (2017). Double-cropped fields were sampled August 4 to 5 and August 24 to 26 (2015), August 12 and August 25 (2016), and July 26 and August 22 (2017). Twenty locations, which were arbitrarily selected to ensure complete coverage of the field, were assessed for each field per visit. At each location, a single soybean plant was selected by the evaluator closing his eyes and selecting the first plant touched, and it was assessed for foliar symptoms of SVN. Plants containing any foliar symptoms characteristic of SVN were scored as positive for SVN, and those with no observable symptoms were scored as negative. A symptomatic leaflet was collected for each positive visual observation, placed into a plastic bag on ice, and

${ }^{\dagger}$ Corresponding author: N. M. Kleczewski; E-mail: nklecz1980@gmail.com

Funding was provided by the Delaware Soybean Board.

(C) 2018 The American Phytopathological Society sent overnight for confirmation of SVNV using enzyme-linked immunosorbent assays (Agdia, Loveland, IN). ELISA indicated that all symptomatic foliage was positive for SVNV. Disease incidence, defined as the number of plants with foliar symptoms of SVN divided by 20 and multiplied by 100, was calculated for each field. Data were $\log$ transformed and analyzed using a repeated measures general mixed model with field as a random factor and production system (full season versus double cropped) and growth stage (vegetative versus reproductive) and their interaction as fixed factors, with field nested within growth stage, using JMP version 13 software (SAS, Cary, NC).

A preliminary analysis indicated no significant impact of year on SVN incidence, and therefore it was not included in the model. Average disease incidence for 2015, 2016, and 2017 was 19.0, 17.0, and $15.5 \%$, respectively. Disease incidence was impacted by main effects of production system $(P<0.0001)$ and soybean growth stage $(P=0.002)$; their interaction was not significant $(P=0.400)$. When averaged across growth stage, SVN incidence in full-season soybeans was $50 \%$ lower than for double-cropped soybeans (Table 1). Disease incidence was greater in plants assessed during early reproductive growth stages compared with vegetative growth stages (Table 1). These data indicate that SVN is prevalent in soybean of the Chesapeake Bay region, and planting system or planting date may impact the amount of SVN in fields. In addition, SVN can be detected at low levels during vegetative stages of growth, but it is more prevalent during the reproductive growth stages (Table 1). Additional research should be conducted to determine the association between (i) planting system or date and (ii) SVN symptom expression and oil content in high-oleic acid soybeans. Symptoms of SVN on soybean are observable in Delaware at early stages in growth and can be easily misidentified as fungal foliar diseases. Scouts or growers observing foliar symptoms of chlorosis during soybean reproductive stages

TABLE 1

Least squares means \pm standard errors for main effects of production system and soybean growth stage on incidence of soybean vein necrosis (SVN) disease assessed from $\mathbf{8 8}$ soybean fields in Delaware from 2015 to 2017

\begin{tabular}{lccccc} 
& \multicolumn{2}{c}{ Production system } & & \multicolumn{2}{c}{ Soybean growth stage ${ }^{\mathbf{a}}$} \\
\cline { 2 - 3 } \cline { 6 - 6 } Incidence (\%) & $\begin{array}{c}\text { Full } \\
\text { season }\end{array}$ & $\begin{array}{c}\text { Double } \\
\text { cropped }\end{array}$ & $\begin{array}{c}\text { Vegetative } \\
\text { (V3 to V5) }\end{array}$ & $\begin{array}{c}\text { Reproductive } \\
\text { (R1 to R3) }\end{array}$ \\
\hline SVN incidence & $11.6 \pm 3.1$ & $22.8 \pm 3.2$ & & $4.5 \pm 3.3$ & $29.8 \pm 3.1$ \\
\hline
\end{tabular}

${ }^{\text {a }}$ Vegetative growth stage $=$ the number of unfolded trifoliate leaves present on the plant; R1 = beginning flowering, with at least one flower present at any node; R2 = full flowering; and R3 = beginning pod, for which pods are $5 \mathrm{~mm}$ at one of the four uppermost nodes (Fehr and Caviness 1977). 
should consult a diagnostic lab service to determine if symptoms are owing to SVN and avoid unneeded management tactics.

\section{Acknowledgments}

Special thanks to Christopher Ramage, Nathan Smith, Bill Cissel, and Don Seifrit for assistance with the surveys and to Alyssa Collins, Kate Everts, and two anonymous reviewers assisting with earlier drafts of this article.

\section{Literature Cited}

Anderson, N. R., Irizarry, M. D., Bloomingdale, C. A., Smith, D. L., Bradley, C. A., Delaney, D. P., Kleczewski, N. M., Sikora, E. J., Mueller, D. S., and Wise, K. A. 2017. Effect of soybean vein necrosis on yield and seed quality of soybean. Can. J. Plant Pathol. 39:334-341.
Fehr, W., and Caviness, C. E. 1977. Stages of soybean development. Special report 80. Iowa State University Cooperative Extension Service, Ames, IA.

Groves, C., German, T., Dasgupta, R., Mueller, D., and Smith, D. L. 2016. Seed transmission of Soybean vein necrosis virus: The first tospovirus implicated in seed transmission. PLoS One 11:e0147342.

Keough, S., Han, J. L., Shuman, T., Wise, K., and Nachappa, P. 2016. Effects of Soybean vein necrosis virus on life history and host preference of its vector, Neohydatothrips variabilis, and evaluation of vector status of Frankliniella tritici and Frankliniella fusca. J. Econ. Entomol. 109: 1979-1987.

Zhou, J., Kantartzi, S., Wen, R.-H., Newman, M., Hajimorad, M., Rupe, J., and Tzanetakis, I. 2011. Molecular characterization of a new tospovirus infecting soybean. Virus Genes 43:289-295.

Zhou, J., and Tzanetakis, I. E. 2013. Epidemiology of Soybean vein necrosisassociated virus. Phytopathology 103:966-971. 